HASAN ŞAHIN, Ph.D. Candidate

E-mail: sahinhasan@itu.edu.tr

Istanbul Technical University

Mechanical Engineering Department

34437 Gumussuyu Istanbul, Turkey
Traffic Engineering

Original Scientific Paper

Submitted: 29 Dec. 2016

Accepted: 3 July 2017

\title{
COLLISION AVOIDANCE VIA ADAPTIVE TRAJECTORY CONTROL IN CASE OF A SUDDEN DECREASE IN THE MAXIMUM ROAD FRICTION COEFFICIENT
}

\begin{abstract}
This study analyses an Adaptive Trajectory Control (ATC) system in case of a sudden change in $\mu_{\max }$ (maximum tyreroad friction coefficient) during an emergency lane change manoeuvre in order to maintain the driving safety. Autonomous front wheel steering (FWS) systems have been developed for emergency steering situations. The trajectory design is also a part of these systems. Moreover, in this study ATC has been designed by sensing $\mu_{\max }$ to complete the emergency steering manoeuvre successfully. Therefore, the originality of this paper arises from the necessity of a trajectory change in case of a sudden change in $\mu_{\max }$ to minimize the distance between the desired and the actual path. Suitable cases were designed by using a two-track model in IPG/ CarMaker (MATLAB/Simulink). Results show that ATC could be used during an emergency steering manoeuvre in case of a sudden decrease in $\mu_{\max }$ as it can be advantageous in certain critical traffic situations. Therefore, ATC could be used as an alternative system instead of Electronic Stability Program.
\end{abstract}

\section{KEY WORDS}

Adaptive Trajectory Control; active safety; advanced driver assistance systems; collision avoidance; intelligent transportation systems; autonomous vehicle systems;

\section{INTRODUCTION}

For a long time active safety systems have been introduced to avoid collision via braking such as braking assist and corresponding stability control systems [1]. It is predicted that responses to expected events are faster than responses to unexpected events [2, 3]. Therefore, active safety systems have a significant role for avoiding possible collision with an autonomous braking system [4, 5]. Most of the active safety systems try to control longitudinal dynamics of the vehicle such as advanced emergency braking system, although in some cases active longitudinal control was not sufficient to avoid a possible collision [6]. For example, if the speed of host vehicle is more than $70-80 \mathrm{~km} / \mathrm{h}$ on the dry asphalt, the distance required to avoid collision with an obstacle via a steering manoeuvre is always less than the distance required to avoid collision with an obstacle via a braking manoeuvre [7]. Furthermore, a braking manoeuvre without steering was recognized as the most frequent first natural response of the drivers. Also, a steering manoeuvre could be observed if only a braking manoeuvre was detected as insufficient by the drivers [8-11]. Although a single steering manoeuvre could avoid a possible collision, it could be the second choice because of the lack of experience of the drivers for applying high lateral accelerations $[9,12]$. Therefore, one of the most important decision error occurs, which also depends on a delayed recognition by the drivers [13-15]. This error could be solved by an autonomous steering system. On the other hand, an autonomous steering system has not been put into practice as it is still in research \& development phase [15]. Many control strategies of an autonomous steering system have been developed over a long time such as MacAdam's model in [16], Sharp's model in [17], Salvucci's model in [18], Gordon's model in [19], and Ryu's model in [20]. Most of the control strategies use front wheels as instruments to follow the desired trajectory by comparing the yaw, yaw rate, lateral position and head angle of the vehicle [16-21]. By the way, $\mu_{\max }$ is an important factor in the design of these trajectories. For example, a sudden change in $\mu_{\max }$ may lead to a collision if the trajectory is not controlled properly. In the construction of ATC, the estimation of $\mu_{\max }$ is very significant. If $\mu_{\max }$ is estimated continuously during an emergency steering manoeuvre, the corresponding trajectory could be designed online. In order to estimate $\mu_{\text {max }}$, many parameters should be observed such as side slip angle, normal and lateral forces acting on tyre, velocity of the vehicle, etc. [22-28]. Velocity of the vehicle could be observed from speedometer, rear wheel angle sensors or GPS. If the default vehicle mass is known, normal forces acting on tyres could be estimated by considering the load transfer during cornering. By the assists of GPS receiver and the gyroscopes, the longitudinal \& lateral acceleration of the vehicle and yaw rate could be measured and therefore the side slip angles could be calculated. After side slip angles are calculated, the lateral forces acting on tyres could be calculated by mapping the change of 
cornering stiffness of tyres from a look-up table during load transfer. Therefore, the estimation of mu could be done via measuring lateral and normal forces acting on tyres. As a result of this estimation, the vehicle stability could be maintained via ATC during an emergency steering manoeuvre.

\section{METHODOLOGY}

Before examining ATC, the differences between emergency steering and braking manoeuvres for the autonomous FWS system will be explained briefly. After that, the decision-making for the activation of ATC will be mentioned. For the usage of this controller, a vehicle model is necessary. The trial vehicle model, which is a bicycle model, will be explained in detail. After that, the validation model, which is a two-track vehicle model, will be mentioned briefly. Finally, the control strategy of ATC will be examined at the end of the Method.

\subsection{Emergency steering vs. emergency braking}

As it was mentioned in Introduction, a single braking manoeuvre was recognized as first natural response of the drivers [8-11]. The autonomous FWS system is activated via the steering wheel if only the last point to brake is missed, which is in line with the natural response of the drivers. As illustrated in Figure 1, for avoiding a collision at $100 \mathrm{~km} / \mathrm{h}$ the last point to brake was calculated at 45 metres and the last point to steer via autonomous FWS system was calculated at 22-metre distance to obstacle on dry asphalt $\left(\mu_{\max }=1\right)$. Therefore, the autonomous FWS system was not activated before passing the last point to brake, as the collision could not be avoided without a steering manoeuvre after that.

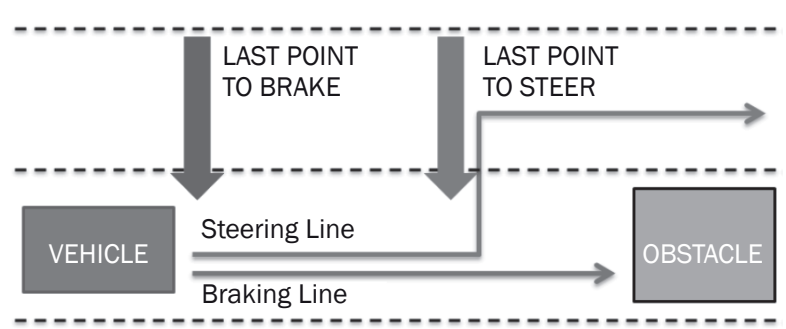

Figure 1 - Last points for emergency steering \& braking to avoid collision at $100 \mathrm{~km} / \mathrm{h}\left(\mu_{\max }=1\right)$

As shown in Equation 1, $d_{\text {brake }}$ stands for the minimum longitudinal distance from the obstacle to avoid collision (last point to brake) via braking [29]. It depends on the average longitudinal deceleration $a_{x(\text { mean) }}$, speed of the vehicle $v_{\text {vehicle }}$ and reaction time $\tau_{\text {reaction. }}$. The average longitudinal deceleration was calculated according to the full braking exercise done in IPG/CarMaker software on dry asphalt. The reaction time was defined as $160 \mathrm{~ms}$ assuming that the vehicle was equipped with a collision warning system such as forward collision warning. This is in line with the studies as the mean reaction time for sound stimulus is $160 \mathrm{~ms}$ [30, 31]. In this study, the vehicle was not equipped with an autonomous braking system and therefore human reaction time was taken into consideration to calculate the last point to brake.

$d_{\text {brake }}=\frac{1}{2 \cdot a_{x(\text { mean })}} v_{\text {vehicle }}{ }^{2}+\tau_{\text {reaction }} v_{\text {vehicle }}$

As shown in Equation 2, $d_{\text {steer }}$ stands for the minimum longitudinal distance from the obstacle to avoid collision (last point to steer) via steering [29]. It depends on the maximum lateral acceleration $a_{y(\text { max })}$, speed of the vehicle $v_{\text {vehicle }}$ and width of the steering manoeuvre, $y_{\text {end }}$. The reaction time was not taken into consideration as the steering manoeuvre was not performed by a human driver. The steering manoeuvre was done via autonomous FWS system and therefore, the reaction time was ignored here.

$d_{\text {steer }}=\sqrt{\frac{2 \cdot y_{\text {end }}}{\mu_{\max } \cdot a_{y(\max )}}} v_{\text {vehicle }}$

\subsection{Decision making}

The proposed adaptive trajectory will be analysed in this study. The trajectories for the dry $\left(\mu_{\max }=1\right)$ and wet asphalt $\left(\mu_{\max }=0.5\right)$ will be compared with the adaptive trajectory on the changeable $\mu_{\max }$. As illustrated in Figure 2, the autonomous FWS system with the trajectories for the dry and wet asphalt cannot avoid collision individually on the changeable $\mu_{\max }$. On the other hand, the autonomous FWS system with the adaptive trajectory could avoid a possible collision.

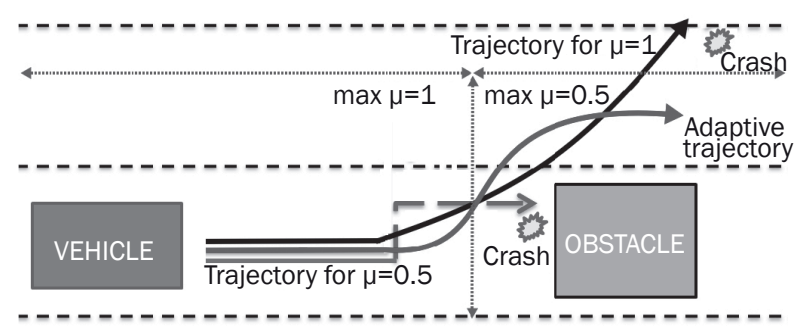

Figure 2 - Adaptive trajectory in case of a sudden decrease in $\mu_{\max }$

There are some limitations in the activation of ATC such as Electronic Stability Program (ESP). The flowchart for the activation of ATC could be seen as illustrated in Figure 3. The first condition for the activation of ATC is missing the last point to brake. The target lane should be free also for an emergency lane change manoeuvre to avoid an unexpected collision with another obstacle or vehicle. In order to fulfil this 
condition, the blind spot detection system or corresponding systems could be used [32]. If the autonomous FWS system begins an emergency lane change with the default calculated trajectory, the system also checks whether $\mu_{\max }$ is changeable. If $\mu_{\max }$ is stable, ATC is not activated. On the other hand, if $\mu_{\max }$ is changed according to $\mu$ estimation, ESP should be observed. If ESP is activated because of the stability loss, ATC will not be activated either. For example, ATC is designed to switch smoothly into the trajectory for the wet asphalt from the trajectory for the dry asphalt. If ESP is active, the vehicle may step out from its actual trajectory and therefore smooth transition into the trajectory for the wet asphalt could be impossible. For this reason, ATC is activated only if ESP is not active. ESP stabilizes the vehicle by performing a single braking on a decided wheel from the observed yaw rate, vehicle velocity and steering angle. On the other hand, ATC system stabilizes the vehicle by changing the trajectory from the observed friction, vehicle velocity and calculated trajectories.

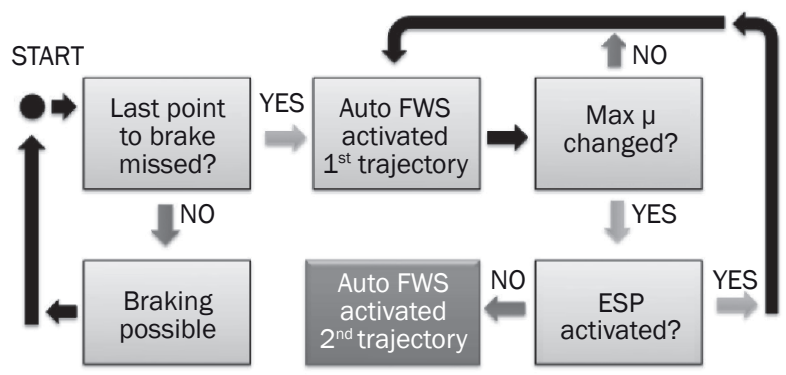

Figure 3 - Decision-making for ATC

\subsection{Vehicle stability criteria via the trial vehicle model (bicycle model)}

The stability of the proposed bicycle model could be identified by observing the tyre side slip angles $\alpha_{i}$ and $\alpha_{r}$, under steer coefficient of vehicle $K_{u s}$, corresponding characteristic speed of the vehicle $V_{c h}$ and $\mu_{\max }$. The under-steer coefficient of vehicle $K_{\text {us }}$ and the corresponding characteristic speed of vehicle $V_{c h}$ could be calculated as shown in Equations 3 and 4 [33, 34]. $W_{i}$ and $W_{r}$ are the weight of the front and rear axle, respectively, and $g$ is the gravitational acceleration in Equations 4 and 5. Furthermore, the relationship between the friction coefficient of the road $\mu$, cornering (lateral) force acting on tyre $F_{y}$ and normal force acting on tyre $F_{z}$ could be seen in Equation 5 [35].

$$
\begin{aligned}
& K_{\text {us }}=\frac{W_{i}}{C_{i}}-\frac{W_{r}}{C_{r}} \\
& V_{c h}=\sqrt{\frac{g L}{K_{u s}}} \\
& \mu=\frac{F_{y}}{F_{z}}
\end{aligned}
$$

The characteristic speed of the vehicle can only exist if the understeer coefficient of the vehicle is above zero [34]. Directional stability of the vehicle depends on the under-steer coefficient of the vehicle. If the value of $K_{u s}$ is designed to be above zero, the vehicle is always directionally stable [34]. By obtaining directional stability the vehicle could be returned back to a straight line path via a sufficient steering manoeuvre [34]. Moreover, of $\mu_{\max }$ is also another factor to identify the stability limits of the vehicle. For a dry asphalt $\mu_{\max }$ is 1.0-1.2 [35]. It could be assumed that the vehicle is in the stable region by staying in the linear region of $\mu$ curve [34]. According to the real tyre data, the linear region of $\mu$ curve could be valid until $50 \%$ of $\mu_{\max }$ [34-35]. On the other hand, the maximum value of the corresponding linear region of $\mu$ curve is assumed as $83 \%$ of $\mu_{\max }$, such as 1.0 in this study. Therefore, in this vehicle model beyond $83 \%$ of $\mu_{\max }$ the vehicle is assumed to be unstable.

The vehicle parameters could be seen as illustrated in Table 1. The under-steer coefficient of the vehicle is above zero; therefore, the vehicle is always directionally stable [34]. As the maximum value of the corresponding linear region of $\mu$ curve is assumed as $83 \%$ of $\mu_{\text {max }}$, the maximum allowable absolute side slip angle of front and rear tyre is 4.3 and 3.8, respectively, to maintain the vehicle stability [34]. The steering ratio from the front tyre to the steering wheel is $1 / 15$ as shown in Table 1.

Table 1 - The vehicle parameters that have an impact on the vehicle stability

\begin{tabular}{|l|c|c||}
\hline Vehicle mass & 1,000 & $\mathrm{~kg}$ \\
\hline Yaw inertia & 1,650 & $\mathrm{kgm}^{2}$ \\
\hline Max friction coefficient of road & 1.2 & - \\
\hline Max linear region of $\mu$ curve & 1.0 & - \\
\hline Distance from cog to front axle & 1 & $\mathrm{~m}$ \\
\hline Distance from cog to rear axle & 1.5 & $\mathrm{~m}$ \\
\hline Cornering stiffness of front tyre & 1,395 & $\mathrm{~N} / \mathrm{deg}$ \\
\hline Cornering stiffness of rear tyre & 1,046 & $\mathrm{~N} / \mathrm{deg}$ \\
\hline Under-steer coefficient & +0.515 & $\mathrm{deg}$ \\
\hline Characteristic speed & 187 & $\mathrm{~km} / \mathrm{h}$ \\
\hline $\begin{array}{l}\text { Steering ratio from front tyre } \\
\text { to steering wheel }\end{array}$ & $1 / 15$ & - \\
\hline $\begin{array}{l}\text { Max/min allowable side slip angle } \\
\text { of front tyre for stability }\end{array}$ & $+/-4.3$ & $\mathrm{deg}$ \\
\hline $\begin{array}{l}\text { Max/min allowable side slip angle } \\
\text { of rear tyre for stability }\end{array}$ & $+/-3.8$ & $\mathrm{deg}$ \\
\hline
\end{tabular}

\subsection{Adaptation to two-track model (CarMaker Model)}

All vehicle parameters (except the cornering stiffness of tyres) explained in the bicycle model have been reserved in the two-track vehicle model. Additionally, the tyre model is included in the two-track CarMaker model. Tyre parameters are shown in Table 2. 
Table 2 - Tyre parameters in two-track (CarMaker) model

\begin{tabular}{||l|c|c||}
\hline \hline Tyre model & RT 225 60 R15 & - \\
\hline Longitudinal force (standstill) & 0.02 & - \\
\hline Lateral force (standstill) & 0.2 & - \\
\hline Velocity limit (standstill) & 0.25 & $\mathrm{~m} / \mathrm{s}$ \\
\hline $\begin{array}{l}\text { Longitudinal force (relaxation } \\
\text { length) }\end{array}$ & 0.05 & $\mathrm{~m}$ \\
\hline Lateral force (relaxation length) & 0.1 & $\mathrm{~m}$ \\
\hline $\begin{array}{l}\text { Aligning torque } \\
\text { (relaxation length) }\end{array}$ & 0.05 & $\mathrm{~m}$ \\
\hline Friction coefficient of road & 1.0 and 0.5 & - \\
\hline Kinematic tyre radius & 0.3084 & $\mathrm{~m}$ \\
\hline Nominal tyre radius & 0.3284 & $\mathrm{~m}$ \\
\hline
\end{tabular}

In addition to tyre parameters, the height of the centre of gravity, which was not used in the bicycle model, was designed at 0.5 metres. The tyre model coming from the magic equations (Pajecka tyre model) is embedded by default in the CarMaker software. Therefore, the stability proof is valuable according to this validation.

\subsection{Control strategy}

As the vehicle models and the corresponding stability criteria were explained in the previous sections, the control strategy can be described. As shown in Figure 4, the whole control model of the system can be seen. There are three types of controllers in this system. The automatic FWS yaw controller and the feedback yaw rate controller are both proportional-integral (PI) controllers that were designed with the same criteria. The steering behaviour of the driver models are not included in the system as the driver is not necessary in a full autonomous vehicle [36]. The automatic FWS system generates the reference steering trajectory depending on $\mu_{\max }$, vehicle speed and the distance to obstacle.

In order to define suitable trajectories for the autonomous FWS system, $\mu_{\max }$ should be measured first.

\subsubsection{The $\mu$ estimation}

To estimate $\mu, F_{y}$ and $F_{z}$ should be calculated continuously.

$$
\begin{aligned}
\wedge F_{z \text { (right })} & =F_{z \text { (front right })}+F_{z(\text { rear right })}-F_{z(\text { front left })}-F_{z \text { (rear left })} \\
& =-2\left(\frac{k_{f}}{e_{f}}+\frac{k_{r}}{e_{r}}\right) \vartheta-2 m \frac{a_{y}}{L}\left(\frac{h_{f} \cdot b}{e_{f}}+\frac{h_{r} \cdot a}{e_{r}}\right) \\
F_{y(\text { front })} & =C_{i} \cdot \alpha_{i} \\
F_{y(\text { rear })} & =C_{r} \cdot \alpha_{r}
\end{aligned}
$$

In order to calculate $F_{z}$ for all wheels, the load transfer should be taken into consideration. For example, if the steering wheel is steered counter clockwise, the normal load on the right wheels will increase. The increase could be seen in Equation 6, where $\vartheta$ is the vehicle body roll angle, $k_{f}$ and $k_{r}$ are the front and rear roll stiffnesses, $e_{f}$ and $e_{r}$ are the front and rear vehicle's track, $h_{f}$ and $h_{r}$ are the front and rear height of roll centres, respectively [27].In order to calculate $F_{y}$ for all wheels, the corresponding cornering stiffnesses and side slip angles of the tyres are necessary as shown in Equations 7 and 8 [33]. On the other hand, actual $F_{y}$ and $F_{z}$ could be observed directly as individual signals in IPG/CarMaker software. By calculating or observing $F_{y}$ and $F_{z}$, actual $\mu$ can be calculated. In order to estimate $\mu_{\max }$, the behaviour of actual $\mu$ should be observed. If $\mu$ starts fluctuating suddenly, it means that at that point $\mu=\mu_{\max }$.

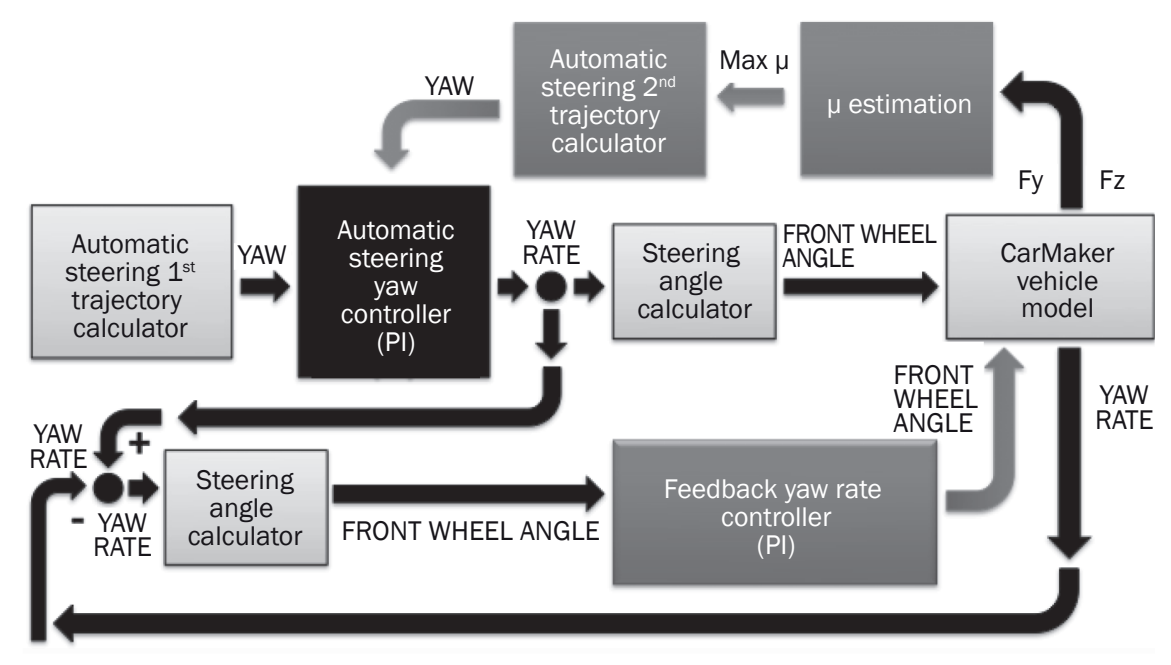

Figure 4 - The control strategy of ATC 


\subsubsection{Trajectory design}

After deciding $\mu_{\max }$, the trajectory of an emergency steering manoeuvre could be calculated as shown in Equation 9 [25, 37]. The width of the manoeuvre is $y_{\text {end }}$, the longitudinal length of the manoeuvre is $x_{\text {end }}$ and the actual position of CoG in the longitudinal axis is $x$ as shown in Equation 9. The coordinates in $Y$ and $X$ axes of any selected point on this trajectory are $y_{\text {des }}$ and respectively $x$ as shown in Equation 9.

$y_{\text {des }}(x)=y_{\text {end }}\left[10\left(\frac{x}{x_{\text {end }}}\right)^{3}-15\left(\frac{x}{x_{\text {end }}}\right)^{4}+6\left(\frac{x}{x_{\text {end }}}\right)^{5}\right]$

The $y_{\text {end }}$ was selected at 3.0 metres for an emergency lane change manoeuvre. The selection of $y_{\text {end }}$ directly depends on the lane width; however, the selection of $x_{\text {end }}$ does not depend on a single parameter because the vehicle stability should be maintained while avoiding a possible collision. As mentioned before, $d_{\text {steer }}$ in Equation 2 stands for the minimum longitudinal distance from the obstacle to avoid collision (last point to steer) via steering [29].

$x_{\text {end }}=\sqrt{\frac{2 y_{\text {end }}}{\mu_{\max } \cdot a_{y(\max )}}} v_{\text {vehicle }}$

The $x_{\text {end }}$ is calculated as shown in Equation 10. In this equation, $\mu_{\max }$ directly affects the maximum lateral acceleration of the vehicle and the tyre sideslip angles, and $v_{\text {vehicle }}$ shows the speed of the vehicle that was defined as $100 \mathrm{~km} / \mathrm{h}$ in the whole study.

As mentioned before, ATC was designed to switch smoothly into the trajectory for the wet asphalt from the trajectory for the dry asphalt. The corresponding trajectories for ATC could be calculated from Equations 9 and 10 depending on $\mu_{\max }$. The only parameter which is different in both trajectories is $\mu_{\max }$. The switching point of the trajectories is the intersection point of the steering wheel angles of the trajectories. The first part of the steering manoeuvre avoids collision to obstacle and the second part stabilizes the vehicle during the lane change. The switching point appears in the second part. These points will be mentioned in detail in the discussion part after presenting the results.

$\omega=\tan ^{-1}\left(\frac{\dot{y}_{\text {des }}}{\dot{x}}\right)$

From now on the trajectory could be calculated as a vehicle position in both $\mathrm{X}$ and $\mathrm{Y}$-axes. On the other hand, the yaw controller needs an input (yaw) to produce an output (yaw rate) as shown in Figure 4. Therefore, the calculated trajectory should be transferred to the corresponding yaw from the vehicle position. The corresponding yaw $\omega$ could be calculated as illustrated in Equation 11 [38]. The $\dot{y}_{\text {des }}$ and $\dot{x}$ are the derivatives of $y_{\text {des }}$ and $x$, respectively, regarding time.

\subsubsection{Controller design}

After calculating the corresponding yaw from the designed trajectory, the yaw controller could be designed with a low pass filter to provide smooth values of yaw rate. As illustrated in Figure 5, the closed loop control model of the yaw controller could be seen. The plant was designed to be a low pass filter between the yaw rate values where $\mathrm{G}$ is the lag time [38]. $\mathrm{G}$ is defined as 0.1 seconds in this study. In order to maintain the yaw control with this plant, two types of controllers were proposed such as proportional-integral (PI) and proportional-derivative (PD) control [38, 39].

The root locus form of the closed-loop control system with PI and PD controllers could be seen in Equations 12 and 13, respectively [39].

$$
\begin{aligned}
& 1+K\left(\frac{8 s+1}{0.1 s^{3}+s^{2}}\right)=0 \\
& 1+K\left(\frac{0.125 s+1}{0.1 s^{2}+s}\right)=0
\end{aligned}
$$

Parameter $K$ in Equations 12 and 13 affects the damping ratio, maximum overshoot and rise time of the controllers [39].

The parameters which have an impact on vehicle stability, could be observed by performing the exact steering manoeuvre described in Trajectory design, such as the maximum absolute yaw rate output, maximum absolute lateral acceleration, maximum absolute steering angle rate, maximum absolute lateral jerk and maximum absolute front/rear tyre side slip as shown in Table 3. Although the duration of the manoeuvre was similar with both PI and PD controllers, the results show that the $\mathrm{PI}$ controller indicated smoother responses than the PD controller as shown in Table 3. The usage of the derivative in the PD controller resulted in an aggressive response. Therefore, the PI controller was selected as the yaw controller of the system to follow the desired trajectory.

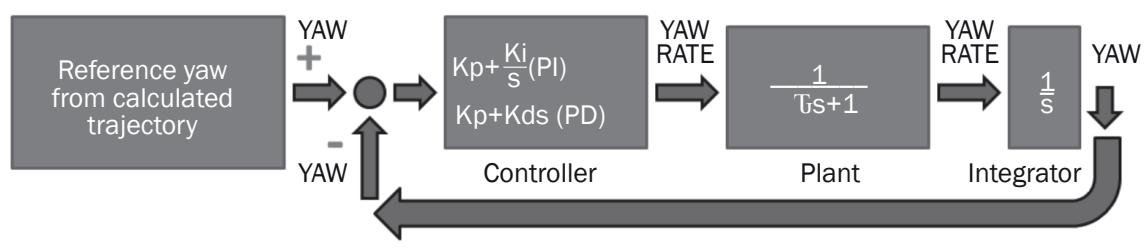

Figure 5 - Yaw controller 
Table 3 - The differences between the PI \& PD yaw controllers for the same steering manoeuvre

\begin{tabular}{||l|c|c||}
\hline \multicolumn{1}{|c|}{ Controller type } & PI & PD \\
\hline \hline Steady state error & $<1 \%$ & $0 \%$ \\
\hline Maximum overshoot & $<5 \%$ & $0 \%$ \\
\hline Rise time & $0.7 \mathrm{~s}$ & $0.7 \mathrm{~s}$ \\
\hline Damping ratio & 0.707 & 1.0 \\
\hline$K$ in Equations 12 and 13 & 0.3206 & 4.0 \\
\hline $\begin{array}{l}\text { Max absolute yaw rate } \\
\text { output }\end{array}$ & $18 \mathrm{deg} / \mathrm{s}$ & $25 \mathrm{deg} / \mathrm{s}$ \\
\hline $\begin{array}{l}\text { Max absolute lateral } \\
\text { acceleration }\end{array}$ & $6.0 \mathrm{~m} / \mathrm{s}^{2}$ & $7.5 \mathrm{~m} / \mathrm{s}^{2}$ \\
\hline $\begin{array}{l}\text { Max absolute steering } \\
\text { angle rate }\end{array}$ & $200 \mathrm{deg} / \mathrm{s}$ & $>1,000 \mathrm{deg} / \mathrm{s}$ \\
\hline Max absolute lateral jerk & $25 \mathrm{~m} / \mathrm{s}^{3}$ & $>1,000 \mathrm{~m} / \mathrm{s}^{3}$ \\
\hline $\begin{array}{l}\text { Max absolute front/rear } \\
\text { tyre side slip }\end{array}$ & $2.6 / 2.75 \mathrm{deg}$ & $3.2 / 3.5 \mathrm{deg}$ \\
\hline
\end{tabular}

There are examples of the controllers in literature such that MacAdam's \& Sharp's model uses the predicted and desired lateral position in [16, 17], Salvucci's model uses the heading angle from the desired points of the lateral position in [18] and Gordon's model uses the yaw rate in [19] as the controller parameters [21]. In this study the desired yaw is calculated from the desired lateral position which is similar to MacAdam's and Sharp's model in [16, 17], and also the calculated yaw is converted to the desired yaw rate as the closed-loop control parameter which is similar to Gordon's model in [19].

The feedback yaw rate controller was also defined as the PI controller which uses the same plant and exact design criteria of the yaw controller. The output of the yaw controller is the yaw rate moving to the steering angle calculator as shown in Figure 4. The calculated yaw rate is the reference for the feedback yaw rate controller after passing the steering angle calculator as shown in Figure 4. Moreover, the yaw rate value should be converted to the front wheel angle for the input of the yaw rate controller. This conversion can be done from the yaw rate $\dot{\omega}$ to the front wheel angle $\delta_{i}$ as shown in Equation 14 [38]. By the way, the corresponding steering wheel angle could be calculated from the front wheel angle by considering the steering ratio mentioned in Table 1.

$\delta_{i}=\frac{\dot{\omega} L}{u}\left(\frac{u^{2}}{v_{c h}^{2}}+1\right)$

\section{RESULTS}

The simulations were done via the validation of IPG/CarMaker software at $100 \mathrm{~km} / \mathrm{h}$ constant vehicle speed without a braking manoeuvre. Two types of $\mu_{\max }$ were used in this simulation such as 0.5 for the wet asphalt, 1.0 for the dry asphalt and both 0.5 \& 1.0 for the changeable asphalt. For the dry asphalt, the last point to brake was calculated as 45 metres and for the wet asphalt, the last point to brake was calculated as 80 metres. Moreover, there are three cases in this simulation as shown in Table 4 . In the first case, the steering manoeuvre for the dry asphalt was performed ( $1^{\text {st }}$ trajectory/black curve) without ATC. In the second case, the steering manoeuvre for the wet asphalt $\left(2^{\text {nd }}\right.$ trajectory/red curve) was also performed without ATC. In the third case, the steering manoeuvre was performed with ATC (includes both $1^{\text {st }} \& 2^{\text {nd }}$ trajectorieblue curve). The colour of all cases was also shown in Table 4 for the figures representing lateral acceleration, yaw rate, roll angle and lateral vehicle position and steering wheel angle.

Table 4 - Three cases representing the colour of cases, status of ATC and trajectory type

\begin{tabular}{||l|l|l|}
\hline \hline \multicolumn{1}{|c|}{ Cases } & \multicolumn{1}{|c|}{ Trajectory Type } & ATC \\
\hline \hline 1 (black) & only for dry asphalt $\left(\mu_{\max }=1\right)$ & OFF \\
\hline 2 (red) & only for wet asphalt $\left(\mu_{\max }=0.5\right)$ & OFF \\
\hline 3 (blue) & for changeable conditions & ON \\
\hline
\end{tabular}

\subsection{Comparison of $1^{\text {st }}$ and $2^{\text {nd }}$ case on the corresponding $\mu_{\max }, 1.0$ and 0.5 , respectively}

Before performing the simulation on the changeable road, it was performed on full dry asphalt and full wet asphalt to observe the differences of both trajectories on their own $\mu_{\text {max }}$. Vehicle lateral acceleration, yaw rate, roll angle and lateral position of both cases were shown in Figures $6 a, 6 b, 6 c$ and $6 d$, respectively during the emergency lane change. In the first case (black), the distance to obstacle for the beginning of the steering manoeuvre was defined as 30 metres on the full dry asphalt ( $1^{\text {st }}$ trajectory). In the second case (red), the distance to obstacle for the beginning of the steering manoeuvre was defined as 36 metres on the full wet asphalt ( $2^{\text {nd }}$ trajectory). As mentioned before, the only parameter which is different in both trajectories is $\mu_{\text {max }}$ In both trajectories, the emergency steering manoeuvre was performed successfully without resulting in a collision or loss of vehicle stability.

\subsection{Comparison of the three cases on the changeable $\mu_{\max }$}

For this time, during 0-277 metres of road $\mu_{\max }$ equals 1.0 , and after the $277^{\text {th }}$ metre of road $\mu_{\max }$ equals 0.5 . In the first case (black), the distance to obstacle for the beginning of the steering manoeuvre was defined at 30 metres on the changeable asphalt ( $1^{\text {st }}$ trajectory). In the second case (red), the distance to obstacle for the beginning of the steering manoeuvre was defined at 36 metres on the changeable asphalt ( $2^{\text {nd }}$ trajectory). In the third case, the 


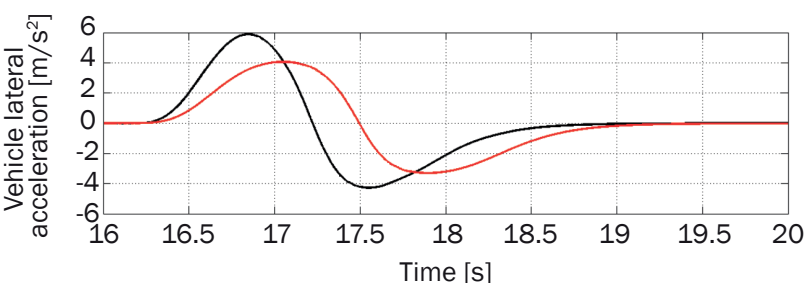

a)

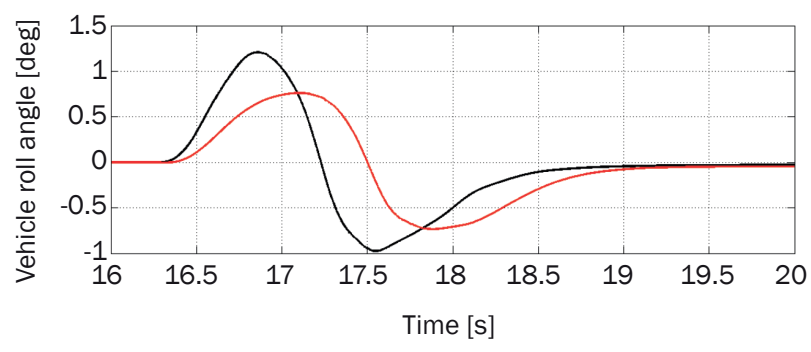

c)

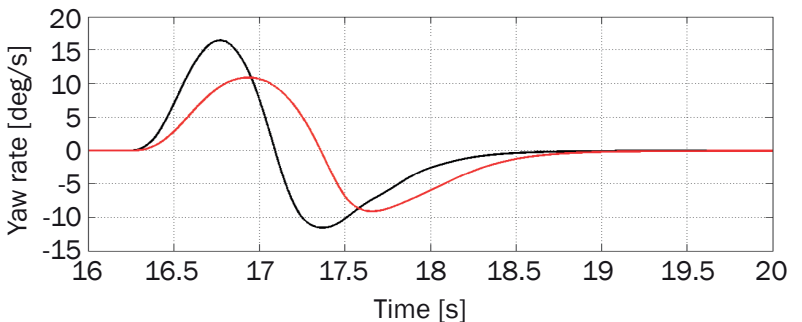

b)

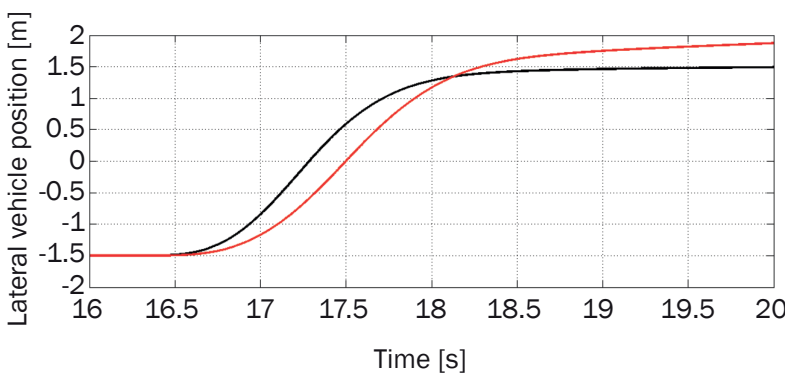

d)

$1^{\text {st }}$ trajectory for dry asphalt
$-\quad 2^{\text {nd }}$ trajectory for wet asphalt

Figure 6 - a) Vehicle lateral acceleration for $1^{\text {st }}$ and $2^{\text {nd }}$ case; b) Vehicle yaw rate for $1^{\text {st }}$ and $2^{\text {nd }}$ case; c) Vehicle roll angle for $1^{\text {st }}$ and $2^{\text {nd }}$ case; d) Vehicle lateral position for $1^{\text {st }}$ and $2^{\text {nd }}$ case

distance to obstacle for the beginning of the steering manoeuvre was defined at 30 metres on the changeable asphalt (ATC using both $1^{\text {st }}$ and $2^{\text {nd }}$ trajectory). The $\mu_{\max }$ changed from 1.0 to 0.5 in the $16.7^{\text {th }} \mathrm{sec}$ ond of the simulation for all cases. ATC followed the $1^{\text {st }}$ trajectory until the $17.4^{\text {th }}$ second of the simulation. It started to follow the $2^{\text {nd }}$ trajectory after that.

As shown in Figure 7a, the collision to obstacle was avoided via the $1^{\text {st }}$ trajectory and ATC. On the other hand, the collision was not avoided via the $2^{\text {nd }}$ trajectory. Moreover, as illustrated in Figure $7 b$, the collision depending on the stability of the vehicle was avoided via the $2^{\text {nd }}$ trajectory and ATC, but not via the $1^{\text {st }}$ trajectory. Therefore, the only case in which all possible collisions were avoided is performed via ATC.

As shown in Figures $8 a$ and $8 b$, lateral acceleration and yaw rate fluctuated when $\mu_{\max }$ changed suddenly in the $16.7^{\text {th }}$ second. As illustrated in Figure $8 \mathrm{c}$, ATC

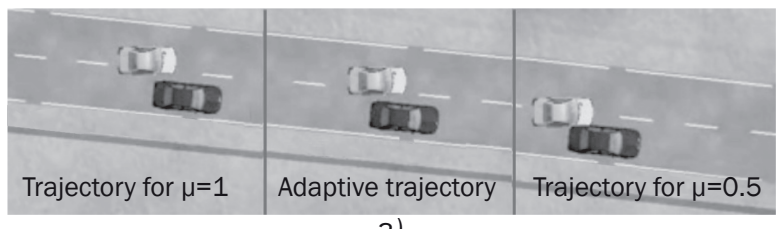

a)

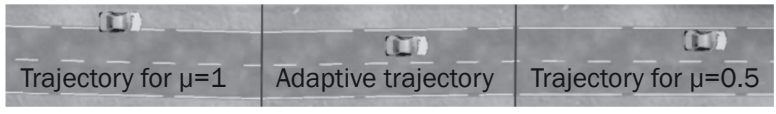

b)

Figure 7 - Positions of the vehicle: a) at the beginning of the emergency steering manoeuvre; b) at the end of the emergency steering manoeuvre followed the $1^{\text {st }}$ trajectory until the $17.4^{\text {th }}$ second and after that switched into the $2^{\text {nd }}$ trajectory. It came to the desired point approximately in the $19^{\text {th }}$ second. Moreover, ATC (blue) followed the same steering angle inputs as the $1^{\text {st }}$ trajectory (blue-black) until the $17.4^{\text {th }}$ second (yellow star) as shown in Figure 8d. On the other hand, ATC switched into the $2^{\text {nd }}$ trajectory (red) after the $17.4^{\text {th }}$ second (yellow star) which is the $2^{\text {nd }}$ intersection point of the steering wheel angles of the $1^{\text {st }}$ and $2^{\text {nd }}$ trajectory. Therefore, ATC seems blue until the $17.4^{\text {th }}$ second (yellow star) and it seems red after that.

The trajectories followed by ATC and the road conditions are illustrated in Figure 9, such as the beginning of the emergency steering manoeuvre, the change point of $\mu_{\max }$, the trajectory switch point and the obstacle avoidance point, respectively. Not only the obstacle was avoided, but also the vehicle lateral stability was maintained via ATC.

\subsection{The $\mu_{\max }$ detection according to $\mu$ estimation}

As shown in Figure 10, the black curve represents $\mu$ estimation of the $1^{\text {st }}$ trajectory on the full dry asphalt. There is no sharp fluctuation in the black curve which represents an unchanged road condition. The blue curve represents $\mu$ estimation of ATC on the changeable asphalt. It could be observed that the blue curve fluctuates sharply in the $16.7^{\text {th }}$ second of the simulation. This is the point of $\mu_{\max }$ detection. After this point, it could be observed that $\mu_{\max }$ equals 0.5 instead of 1.0 . 


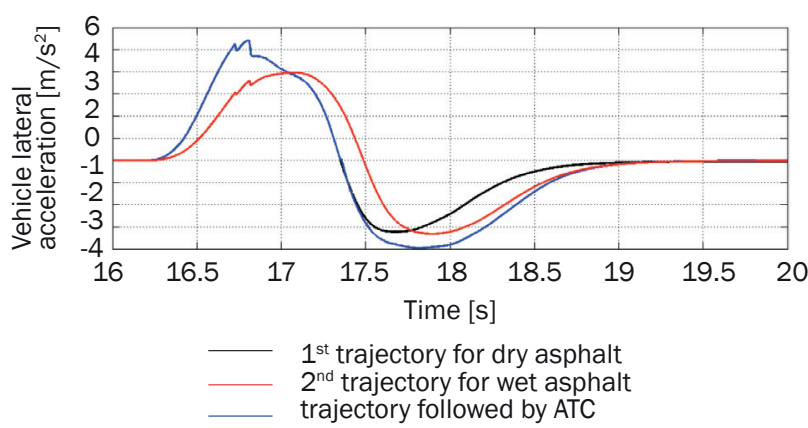

a)

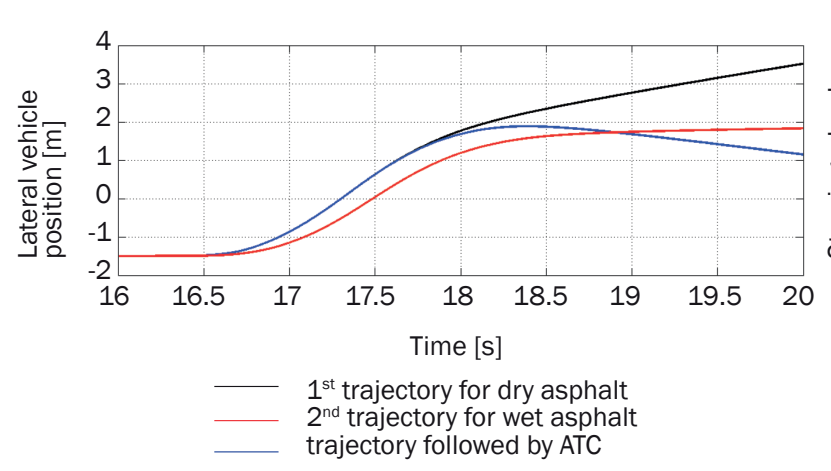

c)

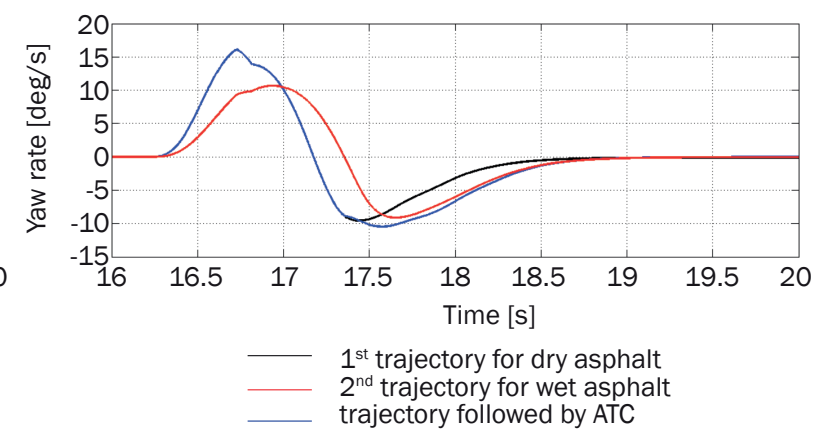

b)

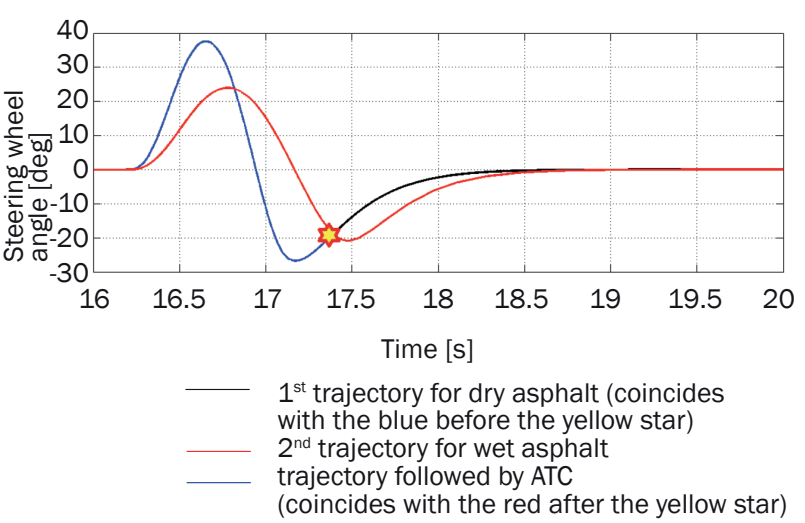

d)

Figure 8 - a) Vehicle lateral acceleration in all case; b) Vehicle yaw rate in all cases; c) Vehicle lateral position in all cases; d) Steering wheel angle in all cases

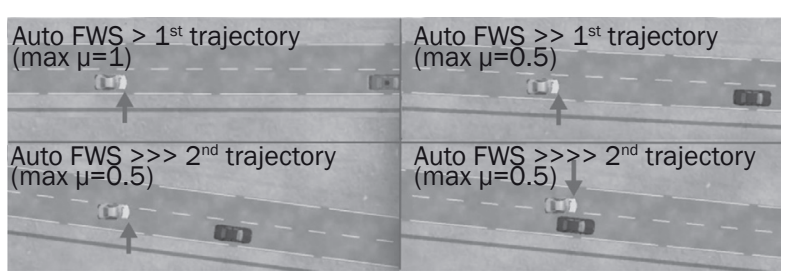

Figure 9 - Trajectory switching points in ATC

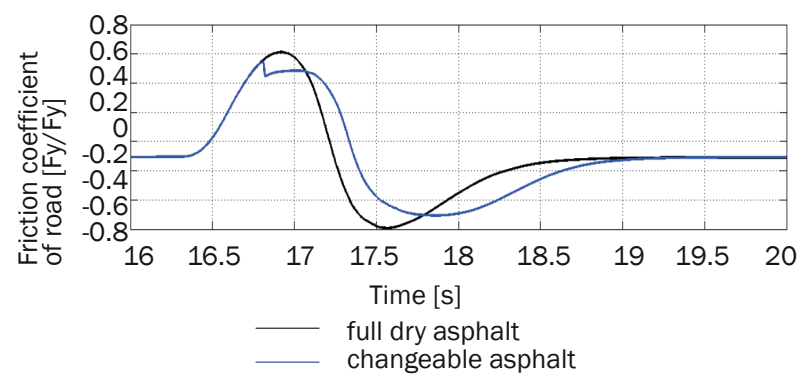

Figure 10 - $\mu$ estimation

\section{DISCUSSION}

This study depends on the perfection of the detection of $\mu_{\max }$. It could be possible to detect it by measuring or calculating $F_{y}$ and $F_{z}$, by using Kalman Filter, by pseudostatic lugre friction model, by dynamic lugre model or by a slip calculation in traction and braking
[22-28]. There are many ways to detect the change in $\mu_{\max }$. In this study, $\mu_{\max }$ was detected by observing $\mu$ estimation. An unexpected change or fluctuation in $\mu$ represents the point where $\mu=\mu_{\max }$.

The most important part after the detection of $\mu_{\max }$ is the specification of the trajectory switch point of ATC. ATC followed the $1^{\text {st }}$ trajectory until the $2^{\text {nd }}$ intersection points of the steering wheel angles of the trajectories as shown with a yellow star Figure $8 d$. The first part of the emergency steering manoeuvre is to avoid collision to obstacle. The second part exists to stabilize the vehicle in order to complete the lane change manoeuvre. Therefore, the ATC switches the trajectory in the second part to stabilize the vehicle.

As also mentioned in the decision-making, ESP should not be active during the first part of the emergency steering manoeuvre in order to perform a smoother trajectory switch via ATC. Although ESP was not active, via the $1^{\text {st }}$ trajectory (for $\mu_{\max }=1$ ) the vehicle could not maintain the stability without ATC. Therefore, ATC is necessary for this kind of situations. On the other hand, if ESP is active because of a stability loss, the trajectory switch could be cancelled via ATC because a loss of the intersection points of the trajectories is possible. And also, if ESP is active, the second part of the emergency steering manoeuvre (stability) can be performed by ESP itself automatically instead of ATC. 


\section{CONCLUSION}

In this study, an Adaptive Trajectory Control (ATC) system was analysed during an emergency lane change manoeuvre. It was observed that ATC can avoid a possible collision while maintaining the vehicle stability. The yaw and yaw rate feedback controller assisted the vehicle to follow the desired trajectory. On the other hand, they are not able to switch into a new trajectory. The advantage of ATC is switching into a suitable trajectory depending on $\mu_{\max }$. Moreover, the simulations were done via the validation of the two-track vehicle model (CarMaker vehicle model) that considers the load transfer during high lateral accelerations. Therefore, ATC was analysed successfully according to vehicle stability criteria. Moreover, the manoeuvres and the change in $\mu_{\max }$ were designed by assuming ESP is inactive. If ESP is active, ATC should be cancelled because of the possibility of discrete transition between trajectories. As a future study, ESP and ATC may be controlled together via intelligent decision-making.

HASAN ŞAHIN, Doktora öğrencisi - Araştırma Görevlisi

E-mail: sahinhasan@itu.edu.tr

İstanbul Teknik Üniversitesi

Makina Mühendisliği Departmanı

34437 Gümüşsuyu İstanbul, Türkiye

\section{ADAPTIF YÖRÜNGE KONTROL SISTEMIYLE DEĞIŞKEN ZEMIN KOSSULLARINDA OLASI BIR KAZANIN ENGELLENMESI}

\section{ÖZET}

Bu çalışmada, ani zemin değişiminde yapılan direksiyon manevrasının kazayla sonuçlanmaması için adaptif yörünge kontrol sistemi (AYK) geliştirilerek IPG/CarMaker (MATLAB/ Simulink) programı üzerinde yapılan simülasyonlarla test edilmiştir. Literatürde otomatik direksiyon manevrası yapan sistemler mevcuttur. Yörünge tasarımı da bu sistemlere dahildir. Ancak, bu çalışmada zemin sürtünme kuvveti satsayısı hesaplanarak zemin şartlarına göre gerekli yörünge değişimi anlık olarak yapılmaktadır. Bu çalışmanın özgünlüğü direksiyon manevrası esnasında zemin koşullarında ani bir değişim olması durumunda anlık yörünge değişiminin yapılmasıdır. Yapılan simülasyonlar sonucu AYK sistemi Elektronik Stabilite Kontrolü'ne alternatif olarak gösterilebilir.

\section{ANAHTAR KELIMELER}

adaptif yörünge kontrol sistemi; aktif güvenlik; sürücü destek sistemleri; kaza önleme sistemleri; akilli taşit sistemleri; otonom araçlar;

\section{REFERENCES}

[1] Thierry P, Kassaagi M, Brissart G. Active safety experiments with common drivers for the specification of active safety systems. Society of Automotive Engineers. 2001; 11 p. Available from: https://www-nrd.nhtsa. dot.gov/pdf/esv/esv17/proceed/00004.pdf
[2] Green M. How long does it take to stop: methodological analysis of driver perception-brake times. Transportation Human Factors. 2000;2(3):195-216.

[3] Engström J, Aust LM, Viström M. Effects of working memory load and repeated scenario exposure on emergency braking performance. Human Factors. 2010;52(5):551-559.

[4] Lee JD, McGehee DV, Brown TL, Reyes, ML. Collision warning timing, driver distraction, and driver response to imminent rear-end collisions in a high-fidelity driving simulator. Human Factors. 2002;44(2):314-335.

[5] Itoh M, Horikome T, Inagaki T. Effectiveness and driver acceptance of a semi-autonomous forward obstacle collision avoidance system. Proceedings of the $54^{\text {th }}$ annual meeting of the Human Factors and Ergonomics Society; 2010 Sep 27-Oct 1; Santa Monica, CA: Human Factors and Ergonomics Society; 2010.

[6] Choi C, Kang Y, Lee S. Emergency collision avoidance manoeuvre based on nonlinear model predictive control. IEEE International Conference on Vehicular Electronics and Safety; 2012.

[7] Jansson J, Johansson J. Decision making for collision avoidance systems. Society of Automotive Engineers. 2002; 10. p. Available from: http://papers.sae. org/2002-01-0403/

[8] Markkula G, Benderius O, Wolff K, Wahde, M. A review of near-collision driver behavior models. Human Factors. 2012;54(6):1117-1143.

[9] Adams LD. Review of the literature on obstacle avoidance manoeuvres: Braking versus steering. Tech. Rep. No. UMTRI-94-19. Ann Arbor: University of Michigan, Transportation Research Institute; 1994.

[10] Lee SE, Llaneras E, Klauer S, Sudweeks J. Analyses of rear-end crashes and near-crashes in the 100-car naturalistic driving study to support rear-signaling countermeasure development. Tech. Rep. No. DOT HS 810 846. Blacksburg: Virginia Tech Transportation Institute; 2007.

[11] Wiacek C, Najm W. Driver/vehicle characteristics in rear-end precrash scenarios based on the General Estimates System (GES). Society of Automotive Engineers. 1999; 7 p. Available from: http://papers.sae. org/1999-01-0817/

[12] Lechner D, Van Elslande P. [Driver behavior in accident situations]. Society of Automotive Engineers; 1997. French

[13] Institute of Traffic Accident Research and Data Analysis. Analysis of human factors in crossing collisions. ITARDA information, No. 56; 2005.

[14] Shimizu M, Usami M, Fujinami H. Development of collision-avoidance assist system JSAE Autumn Convention Proceedings; 2007; No. 148-07. pp. 25-30; 2007.

[15] Hayashi R, Isogai J, Raksincharoensak P, Nagai M. Autonomous collision avoidance system by combined control of steering and braking using geometrically optimised vehicular trajectory. Vehicle System Dynamics. 2012;50:sup1:151-168.

[16] MacAdam C. Application of an optimal preview control for simulation of closed-loop automobile driving. IEEE Trans Syst Man Cybern. 1981;11(6):393-399.

[17] Sharp R, Casanova D, Symonds P. A mathematical model for driver steering control, with design, tuning and performance results. Vehicle System Dynamics. 2000;33(5):289-326. 
[18] Salvucci D, Gray R. A two-point visual control model of steering. Perception. 2004;33(10):1233-1248.

[19] Gordon T, Magnuski N. Modeling normal driving as a collision avoidance process. Proceedings of 8th International Symposium on Advanced Vehicle Control; 2006.

[20] Ryu J, Kim SH, Kim HJ. An emergency obstacle avoidance control strategy for automated highway vehicles. Vehicle System Dynamics: International Journal of Vehicle Mechanics and Mobility. 2002;38(5):319-339.

[21] Markkula G, Benderius O, Wolff K, Wahde, M. Comparing and validating models of driver steering behaviour in collision avoidance and vehicle stabilisation. Vehicle System Dynamics. 2014;52(12):1658-1680.

[22] Zhiquan QI, Taheri S, Wang B, Yu H. Estimation of the tyre-road maximum friction coefficient and slip slope based on a novel tyre model. Vehicle System Dynamics. 2015;53(4):506-525.

[23] Luque P, Mántaras DA, Fidalgo E, Álvarez J, Riva P, Girón $\mathrm{P}$, Compadre D, Ferran J. Tyre-road grip coefficient assessment - Part II: online estimation using instrumented vehicle, extended kalman filter, and neural network. Vehicle System Dynamics. 2013;51(12):1872-1893.

[24] Patel N, Edwards C, Spurgeon SK. Tyre-road friction estimation - a comparative study. Proc. IMechE, Part D: J. Automobile Engineering. 2008;222(12):2337-2351.

[25] Soudbakhsh D, Eskandarian A, Chichka D. Vehicle collision avoidance manoeuvres with limited lateral acceleration using optimal trajectory control. Journal of Dynamic Systems, Measurement, and Control. 2013;135(4):12 p.

[26] Li K, Misener JA, Hedrick K. On-board road condition monitoring system using slip-based tyre-road friction estimation and wheel speed signal analysis. Proc. IMechE Part K: J. Multi-body Dynamics. 2007;221(1):129-146

[27] Doumiati M, Victorino A, Charara A, Lechner D. Latera load transfer and normal forces estimation for vehicle safety: experimental test. Vehicle System Dynamics. 2009;47(12):1511-1533.

[28] Wang J, Alexander L, Rajamani R. Friction estimation on highway vehicles using longitudinal measurements. Journal of Dynamic Systems, Measurement, and Control. 2004;126(2):265-275.

[29] Eckert A, Hartmann B, Sevenich M, Rieth EP. Emergency steer \& brake assist: A systematic approach for system integration of two complementary driver assistance systems. $22^{\text {nd }}$ International Technical Conference on the Enhanced Safety of Vehicles (ESV); 2011 June 13-16; Washington DC; 2011.

[30] Brebner JT. Welford AT, editors. Introduction: an historical background sketch. New York: Academic Press; 1980.

[31] Fieandt K, Huhtala A, Kullberg P, Saarl K. Personal tempo and phenomenal time at different age levels. Reports from the Psychological Institute, No. 2, University of Helsinki; 1956.

[32] Eidehall A, Pohl J, Gustafsson F, Ekmark J. Toward autonomous collision avoidance by steering. IEEE Transactions on Intelligent Transportation Systems. 2007;8(1):84-94.

[33] Veldhuizen TJ. Yaw rate feedback by active rear wheel steering [PhD Thesis]. Eindhoven: Technische Universiteit Eindhoven; 2007.

[34] Wong JY. Theory of ground vehicles. New Jersey: John Wiley \& Sons; 2001.

[35] Ghandour R, Victorina A, Doumiati M, Charara A. Tyre/ road friction coefficient estimation applied to road safety. IEEE 18th Mediterranean Conference on Control \& Automation. 2010 June 23-25; Marrakech, Morocco; 2010. p. 1485-1490.

[36] Benderius O. Modelling driver steering and neuromuscular behaviour [PhD Thesis]. Chalmers: Chalmers University of Technology; 2014.

[37] Nelson W. Continuous-curvature paths for autonomous vehicles. Proceedings of IEEE Int. Conf. Rob. Autom. 1989 May 14-19; 1989. vol. 3. p. 1260-1264.

[38] Rajamani R. Vehicle Dynamics and Control. New York: Springer; 2006.

[39] Franklin GF, Powell JD, Naeini AE. Feedback Control of Dynamic Systems. New Jersey: Pearson; 2006. 